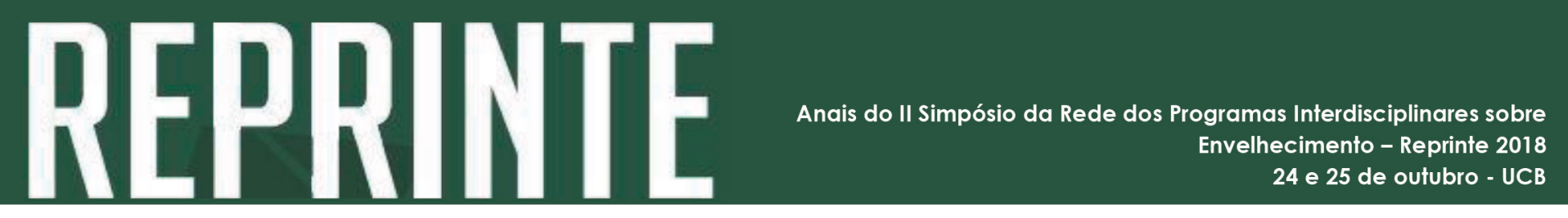

http://dx.doi.org/10.5335/rbceh.v16i1.10468

\title{
22) Oxigenoterapia em idosos: construção e validação de protocolo e aplicativo de indicação e ajuste em clínica médica
}

\author{
Cinthia Leal Dominato ${ }^{1}$; Maria Liz Cunha Oliveira ${ }^{2}$
}

Palavras-chave: Oxigenoterapia inalatória, idoso, hospitalização, protocolo.

\section{Introdução}

A oxigenoterapia inalatória está entre as principais modalidades terapêuticas utilizadas em idosos hospitalizados em clínica médica.

\section{Objetivos}

Caracterizar a aplicação da oxigenoterapia inalatória em idosos hospitalizados em clínica médica na Secretaria de Estado de Saúde do Distrito Federal; construir e validar um protocolo e um aplicativo de indicação e ajuste da oxigenoterapia inalatória para esta população.

\section{Métodos}

Serão realizados três estudos. Estudo 1: estudo observacional, descritivo e transversal, que caracterizará a administração da oxigenoterapia inalatória em idoso hospitalizados. Serão avaliados os indivíduos com mais de 60 anos, em clínica médica, com indicação de oxigênio suplementar, em hospitais da Secretaria de Estado de Saúde do Distrito Federal. Os dados serão extraídos da análise dos prontuários e observação in loco da administração da terapêutica. Estudo 2: estudo metodológico de construção e validação de protocolo de oxigenoterapia inalatória para idosos em clínica médica, a ser elaborado a partir dos resultados obtidos em revisão sistemática sobre o tema. A validação do conteúdo será realizada por comitê de especialistas

Mestranda no Programa de Mestrado em Ciências para a Saúde da Fundação de Ensino e Pesquisa em Ciências da Saúde do Distrito Federal (Fepecs). Endereço para correspondência: SMHN Quadra 03, conjunto A, Bloco 1 Edifício Fepecs. 70.710-907. Brasília, DF, Brasil. Email: cyleal@hotmail.com

2 Professora do Programa de Pós-Graduação em Gerontologia da Universidade Católica de Brasília. Email: lizcunhad@ gmail.com 
e pelo índice de validade de conteúdo. Estudo 3: Desenvolvimento e validação do aplicativo, com base teórica no protocolo de oxigenoterapia, cujo teste de usabilidade será realizado por comitê de especialistas

\section{Resultados}

Espera-se traçar o perfil de utilização da oxigenoterapia em idosos em clínica médica na Secretaria de Estado de Saúde do Distrito Federal, e propor as adequações necessárias a partir da construção e validação do protocolo de indicação e ajuste desta terapêutica para idosos. Para validação do protocolo e testagem do aplicativo, espera-se boa adesão dos profissionais especialistas convidados para o estudo.

\section{Conclusão}

O estabelecimento e validação do protocolo de oxigenoterapia adaptado ao idoso, resultará em melhor relação custo-benefício da utilização do oxigênio. Com o desenvolvimento e testagem do aplicativo, espera-se oferecer uma interface de boa usabilidade para operacionalização da utilização do protocolo estabelecido.

\section{Oxygen therapy in the elderly: construction and validation of protocol and application application and adjustment in medical clinic}

Keywords: Inhaled oxygen therapy, elderly, hospitalization, protocol. 